\title{
17. COMMISSION DE LA LUNE
}

President: Dr D. H. Menzel.

SeCRETARY: B. M. Middlehurst.

First Meeting, 23 August 1967

The President opened the meeting with a few preliminary announcements. The President proposed that Miss B. Middlehurst act as secretary during the XIIIth General Assembly. Ten new members have been proposed for Commission 17. Dr O. Günther retires. Two sessions would be held for consideration of lunar nomenclature for the far side by a working group under the chairmanship of Dr Z. Kopal. On August 26, invited papers and reports on the results of the Surveyors I, II, and III, Orbiters I through IV, and Zond 3 would be given in a meeting open to all Congress participants. A joint session with Commissions 16 and 40 was scheduled for Monday, August 28th under the chairmanship of G. Pettengill to report on radar and radiometric observations of the Moon and planets. The sessions of August 29 and 30 were to be devoted to papers; titles are given below. An additional meeting devoted to lunar transient events was called for August 25. The President then stepped down and the chair was taken by Dr Kopal for the remainder of the meeting for discussion of lunar nomenclature.

\section{SESSION 1 ON LUNAR NOMENCLATURE}

ChaIrman: Dr Z. Kopal.

Members of Working group: A. Dollfus, F. J. Heyden, Z. Kopal, K. Koziel, G. Kuiper, D. Martynov, D. Menzel, A. Mikhailov, M. Minnaert, E. Shoemaker.

Details of the present status of lunar data were surveyed by the Chairman and members of the Working Group, and new ACIC and Russian maps of the far side of the moon were displayed. The coverage, including the recently completed series of photographs by Orbiter $\mathrm{V}$, is now complete. It was stressed that, above all, we need a control system to establish beyond doubt the identity of named or numbered features; also that the reality of the features themselves must be recognized unambiguously. Suggestions made as to the method to be adopted were: (1) that the same method as that used on the front side should be used for the far side (Mikhailov); (2) that we should divide the far side into geometrical regions, perhaps defined by a $10^{\circ} \times 10^{\circ}$ grid, with some flexibility for adjustment to accommodate the borders of topographical features (Kuiper and others), and that key features should be designated for reference within these areas.

The relative merits of the use of names, letters, and numbers as designations for the lunar features were discussed, also the suitability of classes of names (astronomers, allied scientists, and a wider group to include names associated with the present space efforts, particularly those of cosmonauts, astronauts, and others who have lost their lives in space vehicles). The need to avoid undue haste in the adoption of names was stressed (Urey) and suggestions for a waiting period of from five to one-hundred years were made (Minnaert, Urey, and others).

\section{Second Meeting, 24 August 1967}

\section{SESSION 2 ON LUNAR NOMENCLATURE}

Chairman: Dr Z. Kopal.

The second part of the Atlas of the Far Side of the Moon [Aтлас овратной стороны ауны частьп, Издательство 'Наука', Москва, 1967], was distributed to members of the Working Group on lunar nomenclature at the beginning of the meeting. 
The first speaker, Dr Schingareva, referred to the new USSR maps of the far side of the Moon and to the Russian nomenclature already in use. She welcomed the opportunity of comparing the USSR results with the ACIC charts and stated that after reception of the data of Zond 3 in 1965, it became necessary to have some named objects for reference. The principles followed in naming the features were (1) that the same density of named objects as on the front side was desirable; (2) it was not necessary to limit the size of the named objects, but efforts were made to keep the diameter greater than $25 \mathrm{~km}$; the least is $18 \mathrm{~km}$. With regard to the names and referring to $\mathrm{Dr}$ Kuiper's statement in the first session that it was necessary to include names prominent in connection with a variety of sciences, the USSR agrees and their proposal has included the names of Soviet rocket engineers, etc. Examples were given. This tribute is being paid to workers engaged in promoting space research. The USSR is grateful it they can have better data from ACIC so that mistakes can be avoided.

The Chairman then opened a discussion as to the relative merits of classes of names, on the necessity for unambiguous identification, and a description of the coverage by Orbiters I through $\mathrm{V}$. Dr Kuiper pointed out necessary revisions in the light of new material following examination of the names adopted by the IAU at the 1964 meeting for the back side of the moon. He pointed out that many of these features had been identified from full moon photographs and stressed the necessity for good oblique lighting conditions; but at that time only the Zond data (full moon) had been available. In the following discussion, Dollfus, Kopal, Kuiper, Martynov, Menzel, Mikhailov, Minnaert, Shane, Shoemaker, Urey, and others took part. Dr. Shane made the following comments on the American position. The US National Committee on Lunar Mapping and Nomenclature have felt that (1) we should be very conservative in assigning names; (2) because the names are to be permanent, we should try to use names of permanent renown. There should be no hurry, but on the contrary, the scheme should be worked out as fully and carefully as possible. In addition to names, a system of numbers and/or letters would allow for later additions by future generations. A start towards assigning the designations could be made at a later meeting of the IAU.

Dr Minnaert then proposed that a start should be made now and this motion was seconded by Kopal. Dr Menzel stated that he agreed essentially with Dr Minnaert, but that there was a practical problem as to procedure in the time before the next meeting. There is one possibility that does not commit us to any system of names, as the ACIC have already placed about 450 numbers on the charts of the far side as temporary identifications. It is possibly easier to work by number. We should try to keep the naming as simple as possible and avoid duplication, and for the time being, we can do no better than to adopt these numbers to which we can add as better material becomes available. Dr Mikhailov stated that he was in agreement with Dr Minnaert and that we should let the future generations take care of themselves; Dr Menzel's proposal was a very reasonable one. To assign names within a very short time would be perhaps premature. We could appoint a small committee to assign names to be approved by the next IAU meeting. Dr Mikhailov added that it is clear that it is better not to have to revise names as happened in the first excitement of the original probes in 1964. This is not likely to happen again, but it is still wiser to proceed cautiously. A motion that an international committee be set up for such a purpose was proposed by Dr Menzel. Amendments suggested by Dr Kopal were as follows: (1) we should not plan to adopt a greater number of names than on the front side of the Moon; (2) for formations below the minimum size for which names are adopted, designations should be by number. Both amendments were carried unanimously. Dr Menzel's motion was then passed.

Details of nomenclature were then considered. The use of the term thalassoids was debated, but it was generally agreed that for the time being the name 'thalassoides' should not be adopted officially as description of a class of features. Dr Kuiper pointed out that though the far side has such features, the near side has them also and on the near side they are called 'basins.'

The distribution of the ACIC map was then considered. Dr Brunk, Chief of Planetary Astronomy, NASA, USA, distributed 30 copies of the ACIC Lunar Far Side Charts (LFC-2, scale 1:10000000, 1st edition, August 1967) with designated numbers overlaid in red to the members of the Working 
Group. He stated that the chart without overlay is generally available and additional copies can be had by providing name and address. The special edition would be available through Dr Brunk's office (address: Lunar and Planetary Program, Office of Space Science and Applications, National Aeronautics and Space Administration, Washington, D.C., 20546, USA). Fifteen-hundred copies of the map without overlay would be available for distribution to Congress participants after the third session.

Dr Dollfus stressed the importance of continuity in the procedures used for lunar nomenclature and pointed out that the rules previously used by astronomers were reformulated and improved by Commission 16 (Physical Study of Planets) in 1961. The IAU General Assembly in Berkeley in 1961 had adopted a resolution referring to procedures for lunar nomenclature (Trans. IAU., XIB, 235). The text of this resolution was then read by Dr Kopal and reaffirmed by the present committee.

A resolution was then put forward by Dr Menzel and seconded by Dr Mikhailov to be passed to the General Assembly for consideration: that the assignment of names for lunar features should be postponed until the next meeting of the IAU. The resolution was carried unanimously and its formal expression is given in the section 'Resolutions' under No. 8 on page 43.

\section{Third Meeting, 26 August 1967}

\section{PRESENTATION OF LUNAR PROBE DATA}

This session was open to all participants of the Congress

Chairman: D. Menzel.

The following invited papers were presented:

\section{Paper}

The Surveyor spacecraft and its scientific instruments (Presented by E. Shoemaker)

Details of Orbiter spacecraft and methods used for photography

The lunar Orbiter photographs, including those of the limbs and near and far sides

Scientific results regarding the lunar surface from pictures relayed from Surveyors I and III

UV and IR results from Zond 3

Zond 3 Maps

Orbiter IV photographs of sinuous rilles: evidence for the presence of water on the Moon
Author

H. Haglund, Surveyor Project

Manager, Jet Propulsion Laboratory, USA

I. Taback, Lunar Orbiter Spacecraft

Manager, NASA, USA

W. Brunk, NASA, USA

E. Shoemaker, USGS, USA

A. I. Lebedinsky, Moscow University, USSR

V. V. Ševčenko, GAIŠ, Moscow, USSR

H. Urey, La Jolla, USA

At this meeting, 1500 copies of the ACIC map, LFC-2 (1st ed. Aug. 1967) were distributed.

\section{Fourth Meeting, 28 August 1967}

\section{RADAR AND RADIOMETRIC OBSERVATIONS OF THE MOON AND PLANETS}

Chatrman: G. Pettengill.

This session is reported by Commission 40 . 
Fifth Meeting, 29 August 1967

PHYSICAL STUDIES OF THE MOON

Chatrman: D. Menzel.

The following papers were presented:

Paper

Report on the Consolidated Lunar Atlas

Early results from the magnetic field experiment on lunar Explorer 35 (Presented by J. Brant)

Infrared measurements of the lunar surface including

Surveyor I and III results

Data processing of lunar IR results

Thermal response of lunar surface at landing site

(Presented by $\mathrm{H}$. Ingrao)

Lunar surface models including temperature-dependent thermal properties

Comments on the nature of the lunar surface

Opposition effect and the lunar luminescence during eclipses

Orbiter photographs showing morphological correlations at lunar transient event sites

Lunar transient event reports: the need for truly independent confirmation

Lunar volcanism

Origin of lunar craters
Author

G.P. Kuiper

N.F. Ness, K.W. Behannon,

C.S. Scearce, S.C. Cantarano

J. Saari

H. Ingrao, et al.

J.T. Holland, H. Ingrao

J.L. Linsky

D. MacRae

F. Link

B. Middlehurst

P. Moore

G. Fielder

N. Boneff

Sixth Meeting, 29 August 1967

SELENODESY AND RELATED QUESTIONS

ChaIRMan: Dr K. Koziel.

The following papers were presented:

Paper

Absolute and relative heights and shapes on the Moon

On libration

A new secondary selenodetic net (Presented by

E. A. Whitaker)

Theory of physical librations

Shape, size and hypsometric peculiarities

Determination of parameters of the lunar rotation by a method independent of its profile

The annular solar eclipse of May 20, 1966

Cracow libration papers

Lunar libration
Author

J. Hopmann

A.A. Nefediev

D.W.G. Arthur

D. Eckhart

I.V. Gavrilov

A. A. Gorynya

I. M. Demenko, A.S. Duma,

D.P. Duma

K. Koziel

N. Moutsoulas 
Seventh Meeting, 30 August 1967

INSTRUMENTS, PHYSICAL STUDIES, AND OTHER PAPERS

Chatrman: Professor A.I. Lebedinsky.

The following papers were presented:

Paper

A polarizer-discriminator

Role of secondary craters

Role of slopes and albedo

Lunar photometric function

Evidence for the presence of water on the Moon

Laboratory investigation of the proton-excited luminescence of material of types which might exist on the lunar surface

The lunar eclipse of April 24, 1967;

earth- and lunar-based photographs suggest that diffraction in the lower levels of the earth's atmosphere may appreciably increase the brightness of the eclipse during totality
Author
A. K. Korol
B. Levin (1)
B. Levin, L. N. Radlova (2)
G. Fielder
H. Urey
J.E. Geake

B. M. Middlehurst

An additional session was called on August 25 to discuss a proposal by Miss Middlehurst to coordinate efforts of many observatories and other groups of lunar workers in order to promote the greatest efficiency in observing lunar transient events. It is hoped by such a cooperative effort to increase the present small number $(16)(3,4)$ of permanent records and also to obtain records of good quality. The Smithsonian Observatory has offered the use of its satellite communications network, once the communications project is properly funded, to facilitate rapid communication between participating groups. Dr Urey spoke strongly in support of the research and said that volcanic activity must have occurred on the Moon. What is still uncertain is the frequency of lunar events now. Patrick Moore described the work of the British lunar observers who are participating in the watch for events and stressed the need for confirmed observations. Dr Hopmann discussed some of the earlier reports which he said could not possibly be dismissed as erroneous. $\operatorname{Dr} T . W$. Rackham and $\operatorname{Mr}$ E. A. Whitaker described filter techniques. Summing up, Miss Middlehurst said that, in view of the widespread support and interest, the research organization and communications links could be improved in the near future. It is to be hoped that, as in the case of cometary and variable star research, observers with small telescopes in many parts of the world could materially assist the research by providing a constant watch and that, by making use of a system of alerts, institutions with auxiliary apparatus such as spectrographs, photoelectric photometers and other apparatus could more easily obtain good permanent records.

REFERENCES

1. Levin, B. 1967, Astr. Zu., 44, 828.

2. Levin, B., Radlova, L.N. 1967, Astr. Zu., 44, 1296.

3. Middlehurst, B. M. 1967, Icarus, 6, 141 .

4. Middlehurst, B. M. 1967, Rev. Geophys., 5, 185. 